\title{
Correction to: Analysis of medications change in Parkinson's disease progression data
}

\author{
Anita Valmarska ${ }^{1,2}$. Dragana Miljkovic ${ }^{1}$. \\ Nada Lavrač ${ }^{1,2,3}$ • Marko Robnik-Šikonja ${ }^{4}$
}

Published online: 22 June 2018

(C) Springer Science+Business Media, LLC, part of Springer Nature 2018

\section{Correction to: J Intell Inf Syst https://doi.org/10.1007/s10844-018-0502-y}

The original version of this article unfortunately contained a mistake. Figure 4 and Figure 5 in Section 5.4 have mistakenly been switched, while the captions of Figure 4 and Figure 5 are correct and correspond to the references in the text. The corrected figures are shown next page.

The online version of the original article can be found at https://doi.org/10.1007/s10844-018-0502-y.

Anita Valmarska

anita.valmarska@ijs.si

Dragana Miljkovic

dragana.milkovic@ijs.si

Nada Lavrač

nada.lavrac@ijs.si

Marko Robnik-Šikonja

marko.robnik@fri.uni-lj.si

1 Jožef Stefan Institute, Jamova 39, 1000 Ljubljana, Slovenia

2 Jožef Stefan International Postgraduate School, Jamova 39, 1000 Ljubljana, Slovenia

3 University of Nova Gorica, Vipavska 13, 5000 Nova Gorica, Slovenia

4 Faculty of Computer and Information Science, University of Ljubljana, Večna pot 113, 1000 Ljubljana, Slovenia 


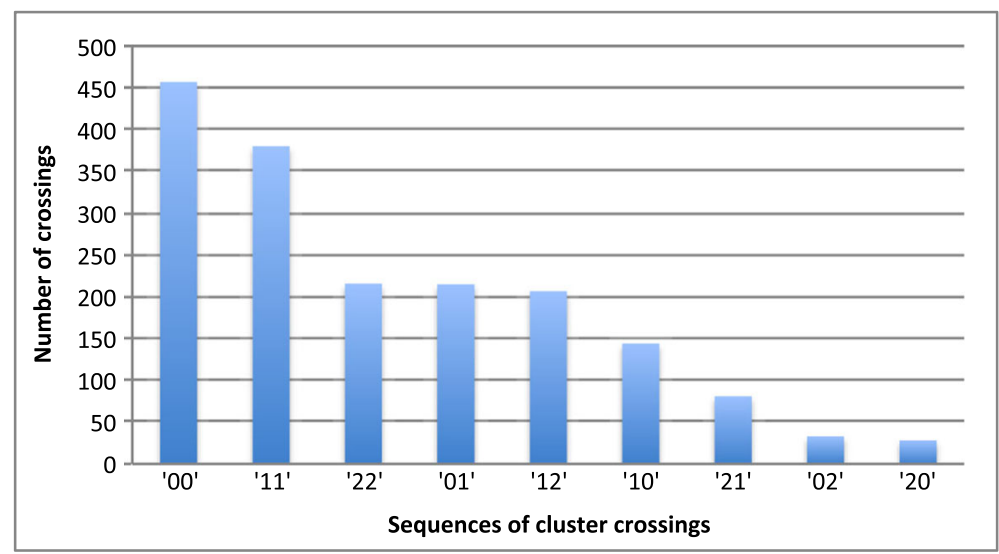

Fig. 4 Histogram resulting from 3-skip-2-gram analysis. The possible cluster crossings are listed on the Xaxis (e.g., 01 indicates that a patient has moved from Cluster 0 to Cluster 1), while the Y-axis represents the number of cluster crossings

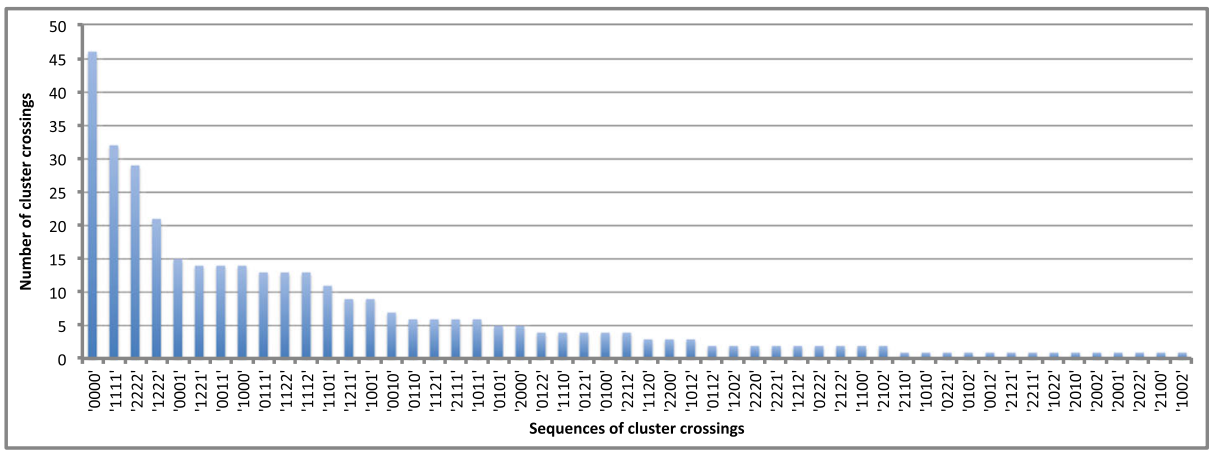

Fig. 5 Histogram resulting from 3-skip-4-gram analysis. The possible cluster crossings are listed on the $\mathrm{X}$-axis and the $\mathrm{Y}$-axis represents the number of cluster crossings 